\title{
Management of the Bronchial Asthma Patients at Practice of Family Doctors
}

\author{
Yuriy Mostovoy, Anna Demchuk*, Tetyana Konstantynovych \\ Propedeutic Department to the Internal Medicine, National Pirogov Memorial Medical University, Vinnytsya, Vinnytsia, Ukraine
}

Email address:

avdemchuk@yahoo.com (A. Demchuk)

${ }^{*}$ Corresponding author

\section{To cite this article:}

Yuriy Mostovoy, Anna Demchuk, Tetyana Konstantynovych. Management of the Bronchial Asthma Patients at Practice of Family Doctors. American Journal of Internal Medicine. Special Issue: New Approaches to Manage Difficult-to-Control, Severe Asthma.

Vol. 8, No. 1, 2020, pp. 45-50. doi: 10.11648/j.ajim.20200801.19

Received: February 9, 2020; Accepted: February 18, 2020; Published: February 28, 2020

\begin{abstract}
With purpose to assess the primary care for bronchial asthma (BA) patients the anonymous survey of 175 family doctors was performed. We established low percent $(2,9 \%)$ of self-depended diagnosis of BA by family doctors. It showed their extremely poor role in the primary BA diagnosis. The most frequently diagnosis of BA made by pulmonologist or allergist $(75,4 \%)$. The management of a patient with BA was performed by a family doctor in collaboration with allergist or pulmonologist in $53,2 \%$ of cases, $70 \%$ family doctors meet with BA patients for control of disease every $1-3$ month. They prescribed correct basis therapy with inhaled corticosteroid (ICS) or combination of ICS with long-action beta agonist most of patients. Misinterpretation of asthma control are showed by most of family doctors. The vast majority of patients (98.8\%) had at least one exacerbation of asthma per year. Only $25 \%$ of family doctors treated patients with BA exacerbation selfdependently. They used nebulization of high doses of bronchodilators and ICS for treatment of BA exacerbation in outpatient setting for $91,4 \%$ of cases. We found low level of prescriptions of systemic corticosteroids for treatment of BA exacerbations in outpatient setting and misunderstanding of systemic corticosteroid therapy. Family doctors need additional educational activities and monitoring adherence to national and international guidelines.
\end{abstract}

Keywords: Bronchial Asthma, Primary Care, Treatment, Asthma Control, Exacerbation

\section{Introduction}

Effective management of patients with bronchial asthma (BA) is one of the most important problem of modern family medicine which is caused by the significant spread of the disease in Ukraine $(0,5 \%)$ and in the world (from $1 \%$ to $18 \%)[1,2]$.

\section{Theoretical Background}

Over the last decade Ukraine has been reforming its medical industry. An institution of the family doctors has been created. Their responsibilities are providing outpatient medical care to all sections of the population, from newborns to the elderly. Primary diagnostics, prescription of the basis therapy, long time management of patients with chronic diseases including BA are performed by family doctors. Only in difficult cases specialists - pulmonologist and/or allergist are involved for patient's management. Family doctor should use the international (GINA 2019) or national guidelines (Order of Ukrainian Ministry of Health № 868 from 09.10.2013 Bronchial asthma. Adapted evidence-based clinical guidelines) grounded on the modern evidence-based medicine for effective management of the BA patients $[2,3]$.

Adherence to the guidelines when managing BA patients allows in most cases to correctly diagnose the disease and to prescribe the most effective basic treatment. It contributes to the achievement of a controlled condition of the patient, providing him a high quality of life.

However, as the results of epidemiological studies show, a controlled condition is not achieved in most BA patients in routine medical practice. Depend on social economic development of country and the level of health care, controlled BA is observed from $8 \%$ till $77 \%$ of patients [412].

In Ukraine, information about how do family doctors care 
for patients with BA in new working conditions and new requirements for them has not been studied. We set ourselves the goal of assessing the state of primary care provision of patients with BA, taking into account current national and international guidelines, by anonymous survey of family doctors.

\section{Material and Methods}

The anonymous survey was performed among 175 family doctors from Vinnytsia. The average length of medical practice of the doctors ranged from 1 to 46 years (averaging $19.6 \pm 12.9$ years). Family doctors with practice less than 5 years were $36(20.6 \%)$, with a duration of practice from 5 to 25 years - $69(39.4 \%)$ and those who worked for more than 25 years - $70(40,0 \%)$.

The survey was conducted using the original questionnaire. It included 20 questions about primary diagnosis and outpatient management of a patient with BA, cooperation with a pulmonologist, allergist, hospital doctors, prescribing basic and rescue medication for therapy, disease control, frequency of occurrence and treatment of exacerbations, including the use of nebulization and systemic corticosteroids for their management on outpatient basis.

Statistical analysis was performed using a standard set of descriptive statistics methods. Differences in the patient management performed by physicians with different practical experience were assessed using cross-tables, chi-square. The criterion of significant was considered to be $p<0.05$. The software package SPSS 12.0 for Windows was used.

\section{Results and Discussion}

At the time of the survey, 1090 patients with asthma were observed by family doctors. On average, there were $(6.2 \pm$ 4.8) patients per doctor.

The diagnosis of asthma in most cases was established by specialists - allergist or pulmonologist or in cooperation with the allergist/pulmonologist and family doctor (Table 1).

Table 1. Making diagnosis of bronchial asthma in primary care setting.

\begin{tabular}{|c|c|c|c|c|}
\hline $\begin{array}{l}\text { Group of doctors according to } \\
\text { duration of practice }\end{array}$ & Family doctor & Allergist/ pulmonologist & $\begin{array}{l}\text { Family doctor and } \\
\text { allergist / pulmonologist }\end{array}$ & During hospitalization \\
\hline$<5$ years $(\mathrm{n}=36)$ & $2(5,6 \%)$ & $28(77,8 \%)$ & $5(13,9 \%)$ & $1(2,8 \%)$ \\
\hline $5-25$ years $(n=69)$ & $2(2,9 \%)$ & $56(81,2 \%)$ & $5(7,2 \%)$ & $5(7,1 \%)$ \\
\hline$>25$ years $(n=70)$ & $1(1,4 \%)$ & $48(68,6 \%)$ & $9(12,9 \%)$ & $15(21,4 \%)$ \\
\hline Total $(n=175)$ & $5(2,9 \%)$ & $132(75,4 \%)$ & $19(10,9 \%)$ & $21(12,0 \%)$ \\
\hline $\mathrm{P}$ & 0,112 & 0,204 & 0,432 & 0,101 \\
\hline
\end{tabular}

Family doctors with duration of practice longer 25 years hospitalized every fifth patient for BA diagnosis. Doctors with smaller experience of work made BA diagnosis in most cases together with allergist/pulmonologist performing outpatient investigations. But lower percent $(2,9 \%)$ of selfdepended diagnosis of BA by family doctors shows their extremely role in the primary BA diagnosis.

In most cases, the management of a patient with BA was performed by a family doctor in collaboration with allergist or pulmonologist, regardless of the experience. This is a positive phenomenon (Table 2). Less than third of family doctors noted they did not treat patients with BA, because they were managed by a pulmonologist or allergist. Only a small number of general practitioners $(16.2 \%)$ monitored BA patients self-dependently.

Table 2. Management of outpatients with bronchial asthma.

\begin{tabular}{|c|c|c|c|c|c|}
\hline Group of doctors according to duration of practice & $<5$ years $(n=36)$ & $5-25$ years $(n=69)$ & $>25$ years $(n=70)$ & Total $(n=175)$ & $\mathbf{p}$ \\
\hline Family doctor & $6(16,7 \%)$ & $13(19,1 \%)$ & $9(13,0 \%)$ & $28(16,2 \%)$ & 0,305 \\
\hline Allergist/pulmonologist & $14(38,9 \%)$ & $20(29,4 \%)$ & $17(24,6 \%)$ & $51(29,5 \%)$ & 0,445 \\
\hline Family doctor and allergist/pulmonologist & $15(41,7 \%)$ & $34(50,0 \%)$ & $43(62,3 \%)$ & $92(53,2 \%)$ & 0,212 \\
\hline \multicolumn{6}{|c|}{ Frequency of family doctor meetings with bronchial asthma patients } \\
\hline Once a month & $7(19,4 \%)$ & $24(34,8 \%)$ & $21(30,0 \%)$ & $52(29,7 \%)$ & 0,107 \\
\hline Every three months & $19(52,8 \%)$ & $22(31,9 \%)$ & $29(41,4 \%)$ & $70(40,0 \%)$ & 0,201 \\
\hline Every year & $3(8,3 \%)$ & 0 & 0 & $3(1,7 \%)$ & 0,505 \\
\hline Only in case of exacerbation & $2(5,6 \%)$ & $9(13,0 \%)$ & $5(7,1 \%)$ & $16(9,1 \%)$ & 0,339 \\
\hline Without meeting & $1(2,8 \%)$ & $2(2,9 \%)$ & $1(0,1 \%)$ & $4(2,3 \%)$ & 0,552 \\
\hline
\end{tabular}

Most family doctors (about 70\%) contact with BA patients once every 1-3 months, which is enough of monitoring the condition and correct treatment. At the same time, doctors with more experience more frequently meet with patients. This may be due to the closer collaboration between the doctor and the patient, which has developed over prolonged contact.

The vast majority of general practitioners prescribed basic medicines according to current standards of treatment of BA patients. There are inhaled corticosteroids (ICS) and combination drugs that include ICS and long-acting beta2agonists (LABA) (Table 3). 
Table 3. Prescription of basic therapy for bronchial asthma by family doctors.

\begin{tabular}{|c|c|c|c|c|c|}
\hline Group of doctors according to duration of practice & $<5$ years $(n=36)$ & $5-25$ years $(n=69)$ & $>25$ years $(n=70)$ & Total $(\mathrm{n}=175)$ & $\mathbf{p}$ \\
\hline Beclometasone & $5(13,9 \%)$ & $12(17,4 \%)$ & $10(14,30 \%)$ & $27(15,4 \%)$ & 0,075 \\
\hline Fluticasone & $8(22,2 \%)$ & $4(5,8 \%)$ & $3(4,3 \%)$ & $15(8,6 \%)$ & 0,072 \\
\hline Budesonide & $16(44,4 \%)$ & $30(43,5 \%)$ & $33(47,1 \%)$ & $79(45,1 \%)$ & 0,063 \\
\hline Salmeterol/fluticasone & $15(41,7 \%)$ & $37(53,6 \%)$ & $40(57,1 \%)$ & $92(52,6 \%)$ & 0,239 \\
\hline Formoterol/budesonide & $5(13,9 \%)$ & $5(7,2 \%)$ & $5(7,1 \%)$ & $15(8,6 \%)$ & 0,198 \\
\hline
\end{tabular}

The most popular topical steroid prescribed by general practitioners was budesonide (45.1\%). Among fixed combinations, most physicians, regardless of work experience, chose salmeterol / fluticasone (52.6\%).

Formoterol / budesonide has been prescribed by less than $10 \%$ of physicians, although it has been shown to be effective in patients with BA in numerical comparative studies and is recommended for baseline therapy.

The prescription of other drugs for basic treatment of asthma was noted by $30(17.1 \%)$ respondents. They indicated formoterol (16 $(9.2 \%)$ doctors), montelukast (12 (6.9\%)), tiotropium $(5(2.8 \%))$.

The use of formoterol as monotherapy can be dangerous because relieving the symptoms of BA the medicine does not have anti-inflammatory effect, which leads to disease progression and increase risk of cardiovascular events, as a side effect of formoterol. The combination of this medication with ICS avoids the risks and provides complete baseline therapy for asthma.

Montelukast has a powerful antileukotriene effect, so it is successfully used in the case of atopic variant of mild BA.

As recommended by GINA prescribing tiotropium for the treatment of BA is effective in the case of severe uncontrolled disease at the fourth and fifth step for adults with frequent exacerbations. The drug improves the lung function and increases the period without exacerbations [2].

According to the evaluation of the spectrum of rescue medications salbutamol occupied the leading position - 82 $(46.9 \%)$ respondents appointed it. Whereas the use of the ipratropium / fenoterol was indicated by 28 (16.0\%) doctors. Response about rescue medication was absent in the questionnaires of $79(45.1 \%)$ doctors.

BA control is defined as a condition of patient without asthma attack, nocturnal and daily symptoms, rescue medication use not more than 2 times in a week, absence any limitation in the daily activity. The Asthma Control Test (ACT) and the frequency of relief medication (salbutamol, ipratropium / fenoterol) are used to determine the BA control $[2,3]$.

According to the opinion of doctors controlled asthma was determined in most patients - an average of $63.86 \%$. Partially controlled BA was in an average of $23.51 \%$. Non-controlled BA was observed in $10.37 \%$ of patients. These data may indicate a high level of BA control, which corresponds to information from developed countries in Europe, the USA, Japan, where well-controlled asthma is determined in 55$78 \%$ [4, 9-12].

Checking the number of salbutamol used by the patient in one month ranged from 0 to 6 and averaged $1.4 \pm 0.7$ inhalers per month or about 300 doses. In the case of controlled BA, the need for salbutamol does not occur more than twice a week. Doing simple arithmetic calculations, multiplying 4 doses of the drug for 52 weeks, we get 208 doses. That is, in the case of controlled BA, the patient uses no more than one inhaler per year.

Thus, family doctors do not correctly assess the state of control in BA.

According to the doctor's opinion the main reasons for insufficient control of asthma are underestimation of the severity of BA by patients in $71.4 \%$ (125 responses), poor financial condition of the patient in $64.6 \%$ (113 doctors), low level of cooperation with the doctor in 54 (30.9\%) cases. These reasons are related to the peculiarities of the patient's perception of the disease, his understanding of the disease course and the effectiveness of the cooperation with the doctor. Similar factors have been described by researchers from other countries [10, 13, 14].

Ongoing consultative support for BA patients by a family physician in collaboration with a pharmacist according to Gums TH et al (2014) and Ali A et al (2019) resulted in a $30 \%$ reduction in hospitalizations for asthma exacerbations, improvement of ACT score and patient quality of life, increase compliance with the use of ICS and reducing need for systemic corticosteroids $[15,16]$.

The occurrence of BA exacerbations is considered one of the indicators of uncontrolled disease. According to the survey, $98.8 \%$ of patients with asthma have an exacerbation within a year. The largest proportion of patients referred for exacerbations from one to three times per year $(94.8 \%)$ and only $4 \%$ of $\mathrm{BA}$ patients experienced more than three exacerbations per year.

$44(25.1 \%)$ family physicians performed self-dependent treatment of BA patients with non-severe exacerbation. Patients were co-administered with a pulmonologist and family doctors in $37(21.1 \%)$ cases. Treatment of patients with exacerbations of asthma by a pulmonologist alone was noted by $35(20.0 \%)$ respondents. The occurrence of severe exacerbations of asthma requiring inpatient treatment was noted by 59 physicians (32\%), and in $20(11.4 \%)$ cases patients were immediately admitted to the hospital due to the severity of the condition without outpatient treatment. Noneffective therapy of BA exacerbation in outpatient settings by the pulmonologist and family doctor, which subsequently led to worsening of the patient's condition and hospitalization, was noted by 29 (20.6\%) doctors (Figure 1). 


\section{Management of asthma exacerbations}

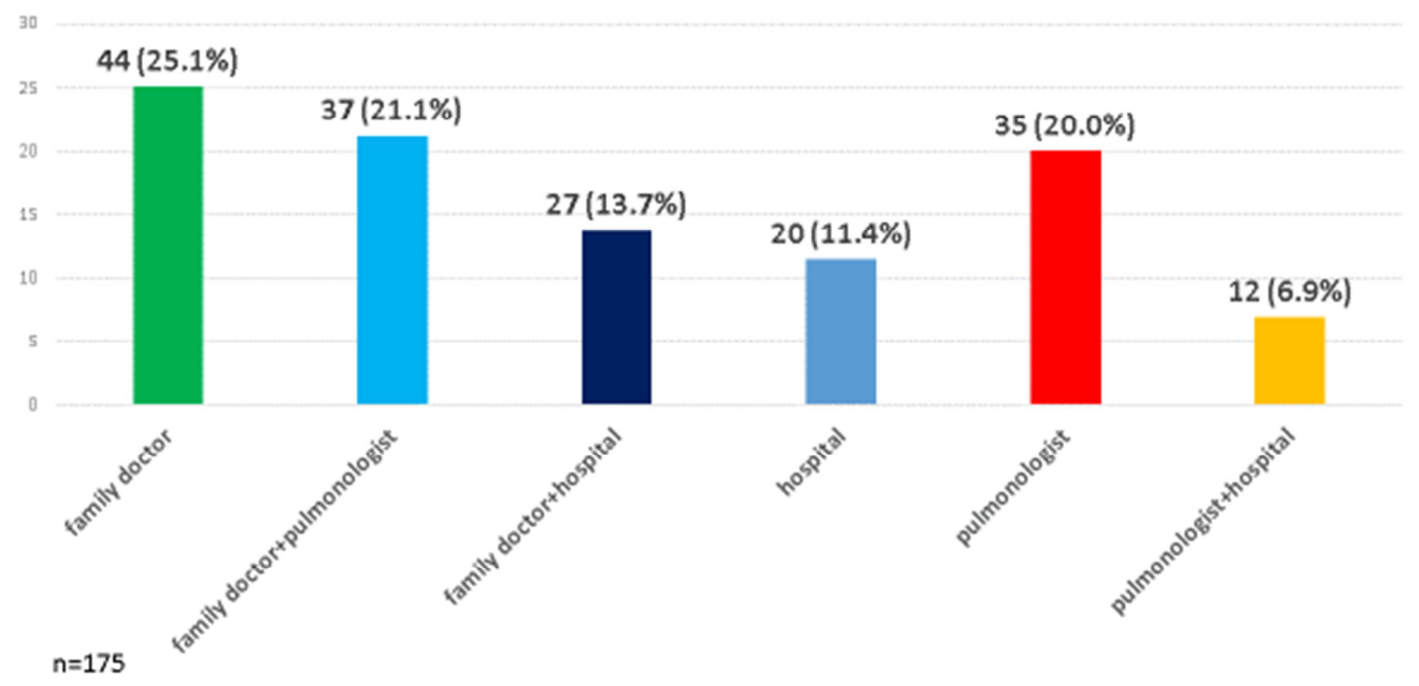

Figure 1. Management of patients with bronchial asthma exacerbations according to survey of family doctors.

An analysis of BA exacerbation treatment in outpatient setting showed the vast majority of physicians, regardless of the length of their practice, used nebulization of inhaled bronchodilator and corticosteroids (Table 4). Patients were most often prescribed nebulization of salbutamol according to current guidelines for the care of patients with mild or moderate BA exacerbation in outpatient setting $[2,3]$. At the same time, such treatment was significantly more often prescribed by doctors with up to 5 years of experience than more experienced $(p<0.05)$, which indicates their better awareness and adherence to modern guidelines for management of BA exacerbations.

Prescribing nebulization of ipratropium / fenoterol for the treatment of exacerbation of asthma was noted by 52 (29.7\%) physicians. Combined bronchodilator drug has a powerful effect on the airway conductivity, affecting the adrenergic and cholinergic mechanisms of bronchospasm, which is necessary in patients with long and severe BA and indicates the presence of a differential approach in the choice of treatment of exacerbation of BA.

Nebulization of high doses of ICS is not indicated in the GINA guidelines for the treatment of exacerbations of BA due to absence of enough current evidence of their efficacy in comparing with systemic corticosteroid [2]. GINA experts recommend the use of oral systemic corticosteroids equivalent to $50 \mathrm{mg}$ of prednisone per day for 5-7 days. Some studies have shown that this method of administration of ICS may be an alternative to systemic hormones, causing a potent local anti-inflammatory effect [17-20]. In Ukraine, we have the positive effect of nebulization of ICS in BA exacerbation.

Table 4. Nebulization in exacerbation of bronchial asthma in outpatient setting.

\begin{tabular}{|c|c|c|c|c|c|c|}
\hline $\begin{array}{l}\text { Group of doctors according } \\
\text { to duration of practice }\end{array}$ & Nebulization & Salbutamol & Ipratropium / fenoterol & Fluticasone & Budesonide & Other medications \\
\hline$<5$ years $(n=36)$ & $34(94,4 \%)$ & $30(83,3 \%)$ & $10(27,8 \%)$ & $18(50,0 \%)$ & $20(55,6 \%)$ & 0 \\
\hline $5-25$ years $(n=69)$ & $64(92,8 \%)$ & $43(62,3 \%)$ & $24(34,8 \%)$ & $31(44,9 \%)$ & $51(73,9 \%)$ & $5(7,2 \%)$ \\
\hline Total $(n=175)$ & $159(91,4 \%)$ & $115(65,7 \%)$ & $52(29,7 \%)$ & $76(43,4 \%)$ & $110(62,9 \%)$ & $10(5,7 \%)$ \\
\hline $\mathrm{P}$ & 0,504 & 0,042 & 0,484 & 0,505 & 0,051 & 0,650 \\
\hline
\end{tabular}

More than half of family doctors indicated that they prescribe nebulization of ICS for the treatment of mild or moderate exacerbation. Among these medications budesonide was preferred due to its potent and rapid antiinflammatory action, good compatibility with bronchodilators and better accessibility in the city's pharmacy network.

Other medicines for nebulization during exacerbation of asthma were mucolytics (ambroxol, hypertonic sodium chloride solution) and antiseptic (decamethoxine).

Prescribing systemic corticosteroids for the treatment of
BA exacerbation was noted by 54 (31.0\%) doctor. However, only $20(11.3 \%)$ general practitioners understood the essence of systemic corticosteroid therapy, indicating that they prescribed dexamethasone in $11(6.3 \%)$ or prednisone in 9 $(5.1 \%)$ cases. Nebulization was interpreted as systemic corticosteroids use by24 (13.7\%) doctors: prescribing budesonide - 11 (6.3\%), fluticasone - 6 (3.4\%), ICS - 7 $(4.0 \%)$. It indicates the need conducting educational activities for family doctors with the control of acquired knowledge and skills.

For the treatment of mild or moderate BA exacerbations 
$78(44.5 \%)$ physicians used other drugs. Montelukast was most frequently indicated in $32(18.2 \%)$ questionnaires, theophylline for intravenous use in $14(8.0 \%)$, mucolytics - in $11(6.3 \%)$, antihistamines - in $10(5.7 \%)$. Montelukast is a medication for basic therapy of BA, so it is inappropriate to treat exacerbations. The use of parenteral theophylline, which was widespread in the last century, is now far inferior to its bronchodilator effect by modern selective beta-agonists or cholinolitics and is dangerous because of the difficulty of controlling adverse reactions of the cardiovascular, central nervous, digestive and other organ systems. The prescription of mucolytics may be appropriate if the patient has a dysfunction of the drainage of bronchial tubes due to viscous sputum accumulation. Antihistamines are not recommended for the treatment of BA exacerbations, but their use may be necessary in patients with atopic asthma.

In some cases, family practitioners indicated the use of antibiotics (3 $(1.7 \%)$ cases. It may be caused by the bacterial etiology of BA exacerbation. The use of fenspiride, ketotiphenum, non-steroid anti-inflammatory drugs, sedative medications are inappropriate because they don't have evidence of effectiveness in the treatment of exacerbation and basic therapy of BA.

\section{Conclusion}

The level of provision of medical care to BA patients by family doctors, in general, is satisfactory, corresponds to current national and international guidelines, both in the choice of basic therapy and in the treatment of exacerbations.

Some disadvantages of primary care were identified, including: low role of family physician in the primary diagnosis and self-management of BA patients; misinterpretation of asthma control by family doctors, low level of cooperation between doctor and patient, low level of prescriptions of systemic corticosteroids for treatment of BA exacerbations in outpatient setting and misunderstanding of systemic corticosteroid therapy.

To eliminate the identified disadvantages additional educational activities should be undertaken among family doctors. Monitoring control of adherence with medical prescriptions and management of BA patient to national and international guidelines should be developed.

\section{References}

[1] Comparative data about respiratory diseases and medical care for patients with diseases of pulmonology and allergology profile in Ukraine 2011 - 2018. National Academy of Medical Science of Ukraine, Medical Statistic Center of Ukraine Ministry of Health of Ukraine State Institution "National Institute of Physiatry and Pulmonology n.a. FG Yanovskiy National Academy of Medical Sciences of Ukraine "Available from: http://www.ifp.kiev.ua/doc/staff/pulmukr2018.pdf.

[2] Global Initiative for Asthma. Global Strategy for Asthma Management and prevention, 2019. Available from: www.ginasthma.org.
[3] Order of Ukrainian Ministry of Health № 868 from 09.10.2013 Bronchial asthma. Adapted evidence-based clinical guidelines. Available from: www.moz.gov.ua/ua/portal/dn_20131008_0868.html.

[4] Price D, Fletcher M, and van der Molen T. Asthma control and management in 8,000 European patients: the REcognise Asthma and LInk to Symptoms and Experience (REALISE) survey. NPJ Prim Care Respir Med 2014; 24: 14009. Published online 2014 Jun 12. doi: 10.1038/npjpcrm.2014.9.

[5] Boonsawat W, Thompson, PJ, Zaeoui U, Samosorn C, Faruqi $\mathrm{R}$ and Poonnoi P. Survey of asthma management in Thailand the asthma insight and management study. Asian Pac J Allergy Immunol 2015; 33: 14-20 DOI 10.12932/AP0473.33.1.2015.

[6] Gebremariam TH, Binegdie AB, Mitiku AS, Ashagrie AW, Gebrehiwot KG, Huluka DK, Sherman CB, Schluger NW. Level of asthma control and risk factors for poor asthma control among clinic patients seen at a Referral Hospital in Addis Ababa, Ethiopia. BMC Res Notes. 2017 Nov 6; 10 (1): 558. doi: 10.1186/s13104-017-2887-z.

[7] Torchyan A. A., Asthma control in Saudi Arabia: Gender implications Allergy Asthma Proc. 2017 May 1; 38 (3): 47-53. doi: 10.2500/aap.2017.38.4035.

[8] Solé D, Sanchez Aranda C, and Wandalsen G F. Asthma: epidemiology of disease control in Latin America - short review. Asthma Res Pract. 2017; 3: 4. Published online 2017 May 11. doi: 10.1186/s40733-017-0032-3.

[9] Bradley E. Chipps \& Robert S. Zeiger \& Alejandro Dorenbaum \& Larry Borish \& Sally E. Wenzel \& Dave P. Miller \& Mary Lou Hayden \& Eugene R. Bleecker \& F. Estelle R. Simons \& Stanley J. Szefler \& Scott T. Weiss \& Tmirah Haselkorn. Assessment of asthma control and asthma exacerbations in the epidemiology and natural history of asthma: outcomes and treatment regimens (TENOR) observational cohort. Curr Respir Care Rep (2012) 1: 259269 DOI 10.1007/s13665-012-0025-x.

[10] Christensen GM, Tomasallo CD, Meiman JG Adult Asthma Control and Self-Management, Wisconsin 2012-2016. WMJ. 2019 Dec; 118 (4): 187-190.

[11] Iikura M, Yi S, Ichimura Y, Hori A, Izumi S, Sugiyama H, Kudo K, Mizoue T, Kobayashi N. Effect of lifestyle on asthma control in Japanese patients: importance of periodical exercise and raw vegetable diet PLoS One. 2013 Jul 9; 8 (7): e68290. doi: 10.1371/journal.pone.0068290. Print 2013.

[12] Calvo E, Trigueros JA, López A, Sánchez G Asthma control in patients attending primary care in Spain (Actis study) Aten Primaria. 2017 Dec; 49 (10): 586-592. doi: 10.1016/j.aprim.2016.12.005. Epub 2017 Apr 12.

[13] Bateman ED. Treatment adherence in asthmatic patients: the last frontier? J Allergy Clin Immunol. 2014; 134 (6): 126970 .

[14] Björnsdóttir US, Gizurarson S, Sabale U. Potential negative consequences of non-consented switch of inhaled medications and devices in asthma patients. Int J Clin Pract. 2013 Sep; 67 (9): 904-910.doi: 10.1111/ijcp.12202.

[15] Gums TH, Milavets G, Carter B. L., Buys L. M. PhysicianPharmacist Collaborative Management of Asthma in Primary Care. Pharmacotherapy 34 (10), October 2014 DOI: 10.1002/phar.1468. 
[16] Ali A, Pena SG, Huggins C, Lugo F, Khaja M, Diaz-Fuentes G. Impact of Group Asthma Education on Asthma Control and Emergency Room Visits in an Underserved New York Community. Can Respir J. 2019 Oct 1; 2019: 5165189. doi: $10.1155 / 2019 / 5165189$.

[17] Reddel HK, Barnes DJ. Pharmacological strategies for selfmanagement of asthma exacerbations Eur Respir J. 2006 Jul; 28 (1): 182-99.

[18] McKeever T., Mortimer K., Andrew Wilson, M. D., Walker S, Brightling C, Skeggs, A, Pavord I, Price D, Duley L., Thomas
M., Bradshaw L, Higgins B. Quadrupling Inhaled Glucocorticoid Dose to Abort Asthma Exacerbations. $N$ Engl J Med 2018; 378: 902-910 DOI: 10.1056/NEJMoa1714257.

[19] Abdullah A. Alangari. Corticosteroids in the treatment of acute asthma. Ann Thorac Med. 2014 Oct-Dec; 9 (4): 187192; doi: 10.4103/1817-1737.140120.

[20] Edmonds ML, Milan SJ, Brenner BE, Camargo CA Jr, Rowe $\mathrm{BH}$. Inhaled steroids for acute asthma following emergency department discharge. Cochrane Database Syst Rev 2012; 12: CD002316.

\section{Biography}

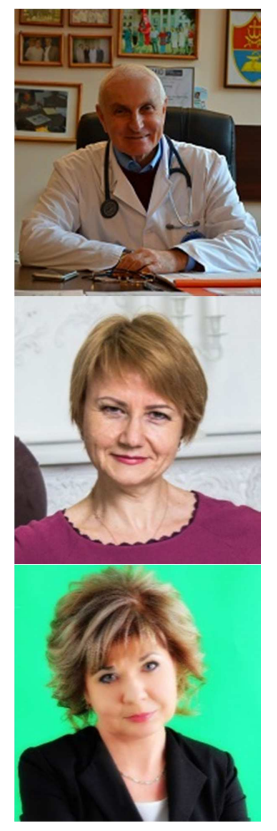

Yuriy Mostovoy (MScD, professor) is a head of the Department of Propedeutics to Internal Medicine of National Pirogov Memorial Medical University, Vinnytsya, Ukraine. He works at the areas of Pulmonology, Asthmatology, Cardiology, Endocrinology, Intensive Care and comorbid pathology. His works have been published in academic journals of Ukraine, the USA, the United Kingdom, Georgia and India, the journals of the European Respiratory Society.

Anna Demchuk (MScD) is a professor of the Department of Propedeutic Department to internal medicine of National Pirogov Memorial Medical University, Vinnytsya, Ukraine. She works at the areas of Pulmonology, Bacteriology and Antibiotics` use, Cardiology, comorbid pathology. Her works have been published in academic journals of Ukraine, Georgia and India, the journals of the European Respiratory Society.

Tetyana Konstantynovych (MScD) is a professor of the Propedeutic Department to internal medicine of National Pirogov Memorial Medical University, Vinnytsya, Ukraine. She works at the areas of Pulmonology, Asthmatology, Cardiology and comorbid pathology, Psychology. Her works have been published in academic journals of Ukraine, Georgia and India, the Journals of the European Respiratory Society. 